\title{
Service and maintenance of marine steam turbogenerators with the assistance of vibration diagnostics
}

\author{
Andrzej Adamkiewicz, Assoc. Prof. \\ Jan Drzewieniecki, Ph.D. \\ Maritime University of Szczecin, Poland
}

\begin{abstract}
The paper discusses the problem of maintenance of the marine steam turbogenerator sets used in power systems on VLCC type oil tankers. The analysis of operation, monitoring and applied diagnostic methods of a selected turbogenerator working in the AT series waste energy system produced by Mitsubishi is presented. The analysis focuses on the applied maintenance method and its credibility and effectiveness in terms of technical assessment. The results of the performed maintenance actions and applied operational procedures making use of technical diagnostics and supported by a wider range of measurement capabilities of external service are presented and evaluated. The range of the study includes the readiness, reliability and safety of the use of turbogenerators being the result of the maintenance performed in accordance with the applied strategy of operation.
\end{abstract}

Keywords: turbogenerator; vibration diagnostic; service; maintenance; condition monitoring; signal analysis

\section{INTRODUCTION}

Steam turbines in auxiliary power units of ship power systems usually perform the function of power generators used during a sea-passage as the main source of electrical energy and cargo pump drive. They are mainly used on vessels specialising in handling, storage and transport of crude oil, such as FPSO (Floating Production, Storage and Offloading) units for instance, and in waste energy recovery systems for VLCC (Very Large Crude Oil Carrier) tankers. They are produced by such manufactures as, inter alia: Mitsubishi Heavy Industries Ltd, Peter Brotherhood Ltd., Shinko Ind. Ltd [2].

During the operation of the marine steam turbogenerators, the processes of their intensive use resulting in the production of the required electric power take place, accompanied by directly related processes of maintenance and monitoring of technical state and suitability to perform tasks, as well as functional, technical and operational readiness, while preserving technical and economic efficiency under given restrictions and disturbances. These processes include:

- identification/determination and preservation of the required technical state,

- technical/maintenance, prevention, and control services, complemented by periodical repairs $[5,9]$.

The above defined maintenance of steam turbines in marine power generation sets includes control methods, measures and systems used for controlling their functional and task-oriented readiness for rational and efficient use at an expected level in given conditions and time, according to their specifications. Here, of high importance is the diagnostics performed with the use of integrated and stand-alone systems and methods of technical diagnostics. It is performed in direct contact with the turbine and plays the superior role in maintenance, with the identification and analysis of its results allowing to control the turbine operation process.

The maintenance strategy is adopted taking into account the existing conditions and resource supplies. For tankers, it is most common to use the planned maintenance strategy (PMS - Planned Maintenance System) which bases on the timeschedule (TBO - Time Base Overhauling) making use of the preventive maintenance (PM - Preventive Maintenance) and elements of technical diagnostics. At present, monitoring the correctness of turbogenerator operation consists in disassemblyfree control of working processes, done via the evaluation of the generated diagnostic signals, including selected representative vibration signals, and their comparison with the reference values. The scope and credibility of the control depend largely on the used measurement equipment and qualifications of the personnel [1].

The aim of the article is to validate the proposed method of steam turbine maintenance with the modification of the set of parameters needed for monitoring the correctness of turbogenerator operation, and justify the need for monitoring the trend of changes of the parameters carrying the highest information capacity. 
a)

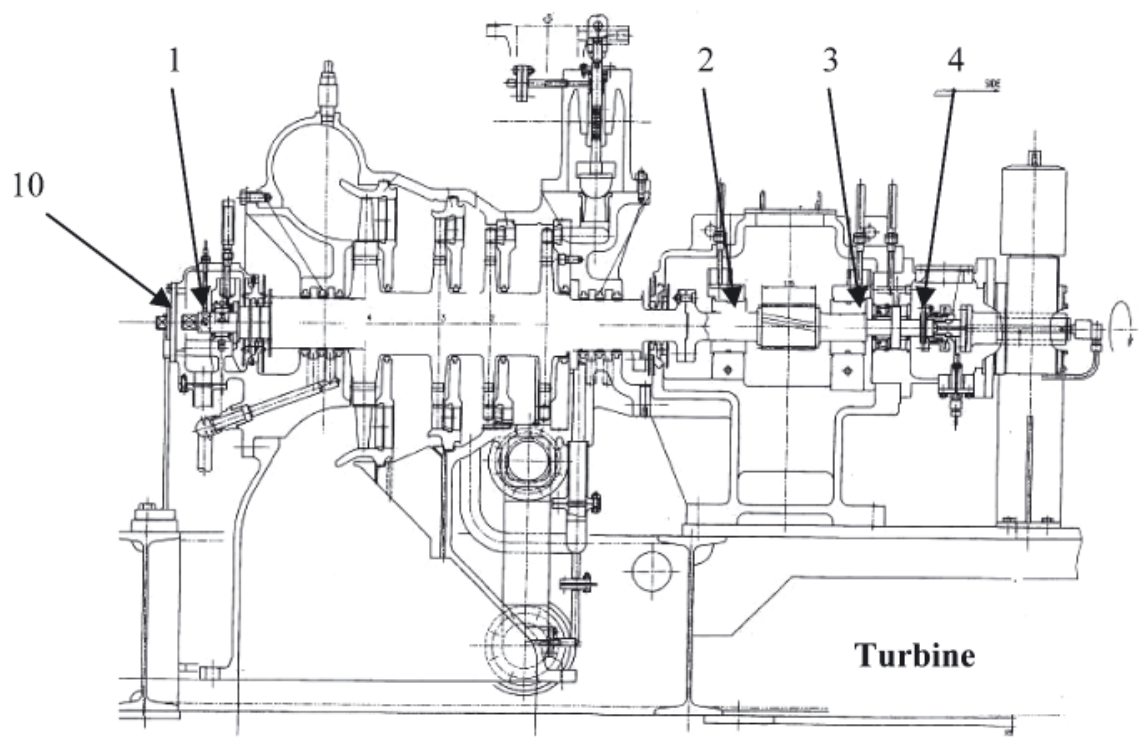

b) 5

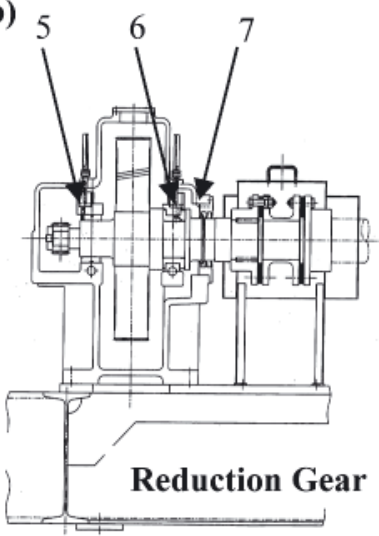

c)

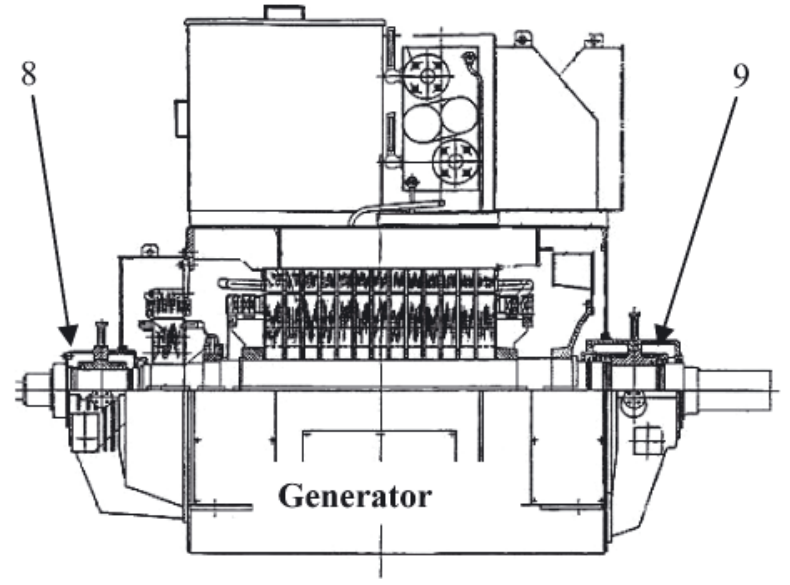

Fig. 1. Longitudinal sections of the turbine (a), reduction gear (b) and generator (c) with the distribution of rotor's relative vibration sensor 10 and identification of bearings in the steam turbogenerator: 1) turbine rotor bearing, 2) pinion bearing turbine side, 3) pinion bearing generator side, 4) turbine thrust bearing, 5) gear wheel bearing turbine side, 6) gear wheel bearing generator side, 7) gear thrust bearing, 8) generator bearing turbine side, 9) generator bearing free end side

\section{THE RESEARCH OBJECT}

The procedures concerning the operation and diagnosis of ship steam turbines have been examined based on a turbogenerator with a $1100 \mathrm{~kW}$ horizontal, four-stage condensation steam turbine AT42M produced by Mitsubishi Heavy Industry Ltd, which drives a synchronous generator via a reduction gear. These turbogenerators are installed in the waste heat recovery systems of a VLCC tankers and work with the exhaust gas boiler co-operating in some operating states with the auxiliary boiler. Leaving the turbine, the superheated steam from the exhaust boiler flows to a vacuum condenser cooled with the seawater. The cross sections of the turbogenerator with its basic components, their bearings and the distribution of the measurement points monitored during its operation are shown in Fig. 1 [3].

As a rule, the turbogenerator is equipped with a monitoring and control system consisting of thermometers measuring local temperatures of the bearings, see Fig. 1: points 1-9, and PTR-M type thermocouples (thermo-resistance bulbs) for their remote monitoring. Thermal and flow parameters of the working media are controlled by thermometers, thermocouples and pressure gauges.

Moreover, the list of elements of the control and measurement system includes: pressure switches with the autostart of the second generator at low live steam pressure, thermostats controlling the oil temperature with the auto start of an independent oil pump in case of low oil pressure, and turbogenerator limit controllers (safety systems) with the emergency stop in case of: oil pressure drop below the lower limit, abnormal/excessive vibrations, high vapour pressure at the inlet to the condenser, and/or an excessive turbine speed (overspeed trip), doubled by the manual emergency "stop".

The turbogenerator is also equipped with a system to measure the turbine rotor shaft vibration in relation to its bearings (relative rotor/ bearing vibration), which is the VM$5 \mathrm{G}$ model, produced by Shinkawa, with an eddy-current sensor shown in Fig. 1 (Section 10). The model can be, at customer's request, extended by an additional sensor. This system allows a remote visualization of displacements (vibrations) and is connected to the general marine power plant monitoring system, with the alarm set at 50 microns, as a standard, and the stop function activated when the limit of 80 microns is exceeded [3].

\section{OPERATIONAL SERVICE AND MAINTENANCE OF TURBOGENERATORS}

The service and maintenance of marine steam turbogenerators during ship operation has the form of continuous (semiautomatic) monitoring process, with the maintenance resulting from working hours. This process consists in simultaneous 
Tab. 1. Sample working parameters of steam turbogenerator working at $750 \mathrm{~kW}$ load

\begin{tabular}{|c|c|c|c|c|}
\hline \multicolumn{2}{|c|}{ State parameter values of working media } & \multirow{2}{*}{$\begin{array}{c}\text { Measured } \\
1.1\end{array}$} & \multirow{2}{*}{$\frac{\text { Alarm/ limits }}{0.5}$} & \multirow{2}{*}{$\frac{\text { Emergency stop }}{-}$} \\
\hline \multirow{4}{*}{ Steam pressure $[\mathrm{MPa}]$} & Main & & & \\
\hline & 1 stage & 0.07 & - & - \\
\hline & Gland & 0.01 & - & - \\
\hline & Exhaust $[\mathrm{MPa}]$ & 0.101 & 0.087 & 0.04 \\
\hline \multirow{2}{*}{ Steam temp. $\left[{ }^{\circ} \mathrm{C}\right]$} & Main & 326 & - & - \\
\hline & Exhaust & 130 & - & - \\
\hline Lube oil pressure [MPa] & Bearings & 0.46 & 0.29 & 0.04 \\
\hline Lube oil temp. $\left[{ }^{\circ} \mathrm{C}\right]$ & System & 48 & 60 & - \\
\hline \multirow{4}{*}{ Medium temp. in cooler $\left[{ }^{\circ} \mathrm{C}\right]$} & LO IN & 48 & - & - \\
\hline & LO OUT & 40 & - & - \\
\hline & Water IN & 43 & - & - \\
\hline & Water OUT & 47 & - & - \\
\hline Bearing temp. $\left[{ }^{\circ} \mathrm{C}\right]$ & Turbine (1) & 59 & 75 & 90 \\
\hline \multirow{4}{*}{ Gear bearing temp. $\left[{ }^{\circ} \mathrm{C}\right]$} & Pinion gear (2) & 59 & 75 & 90 \\
\hline & Pinion gear (3) & 56 & 75 & 90 \\
\hline & Wheel gear (5) & 56 & 75 & 90 \\
\hline & Wheel gear (6) & 58 & 75 & 90 \\
\hline \multirow{2}{*}{ Thrust bearing temp. $\left[{ }^{\circ} \mathrm{C}\right]$} & Turbine (4) & 59 & 75 & 90 \\
\hline & Gear (7) & 58 & 75 & 90 \\
\hline \multirow{2}{*}{ Generator bearings temp. $\left[{ }^{\circ} \mathrm{C}\right]$ at side of } & Turbine (8) & 59 & 75 & 90 \\
\hline & Free end (9) & 59 & 75 & 90 \\
\hline RMS rotor's relative vibration $[\mu \mathrm{m}]$ & Turbine (10) & 27 & 50 & 80 \\
\hline
\end{tabular}

control, recording and archiving of operating parameters and working process parameters. The list of monitored measures with sample values registered at turbogenerator load of 750 $\mathrm{kW}$ and nominal speed of $1800 \mathrm{rev} / \mathrm{min}$, after a total of 57,200 hours from the last overhaul (including safety thresholds for alarms and emergency stops) is given in Tab. 1.

As a rule, most parameters are recorded every four hours and archived automatically by the power plant monitoring system. This rule, however, does not include vibration measurements. In the unmanned engine room, some parameters are entered in the engine room log once a day. A comprehensive report with turbogenerator parameters is analyzed in the technical department of the ship-owner once a month. This report also includes turbogenerator working/maintenance hours, and results of the lube oil analysis. Selected elements of such a report are presented in Tab. 1.

The only element of vibration diagnostics which is part of the standard equipment of the turbogenerator is the measuring system of the bearing related displacement - the relative turbine rotor/bearing vibration. It aims at a continuous control of RMS vibration level of the running turbogenerator, with a possibility to switch the alarm on when the permissible values are exceeded, and stop the turbogenerator in case of exceeding the absolute limits. However, it is not possible to register vibration level changes as a function of time, with further trend analysis.

\section{OPERATIONAL OBSERVATIONS AND MEASUREMENTS}

In the turbogenerator operation process, an increase of relative vibrations from 20 to 30 microns, i.e. by about $50 \%$ compared to those observed in the previous period have been recorded. This fact inspired checking the vibration levels in full range of turbogenerator - TG load. The registered vibration levels confronted with the limits are shown graphically in Fig. 2.

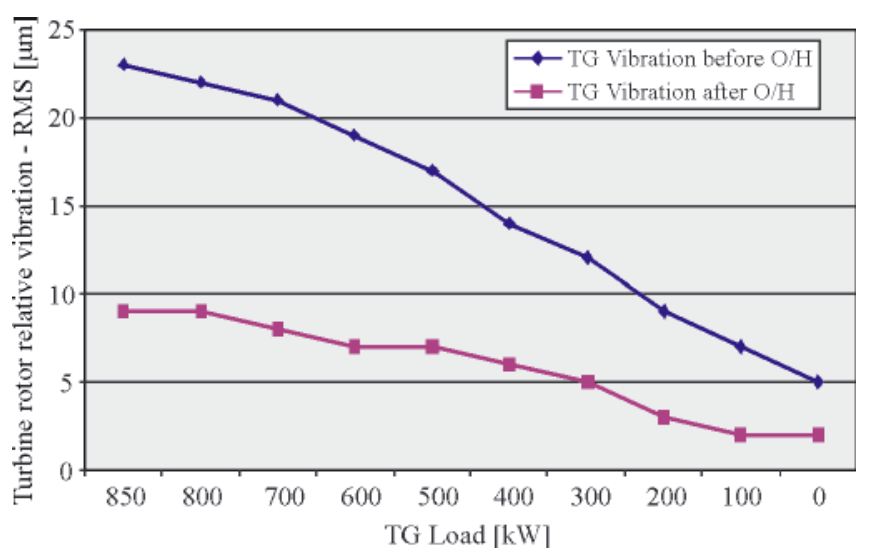

Fig. 2. RMS value changes of turbine rotor's relative vibration signal in the turbogenerator working at $1800 \mathrm{rev} / \mathrm{min}$, for two technical states: before and after overhaul $o / h$

The RMS values of the turbine rotor vibrations as a function of load changes at constant nominal rotational speed increases throughout the entire load range.

The vibrations at smaller rotor speeds than the designed/ nominal value were also inspected, see Fig. 3 for a quasi-static realisation of the turbogenerator start-up process. The RMS values of the turbine rotor vibrations as a function of rotational speed when the turbogenerator worked in the off-load mode also increased throughout the full speed range, which is particularly noticeable in the critical speed range of 800-1100 rev/min.

Comparing the results in the two presented cases with the data from earlier trials/delivery measurements and with the results with similar measurements done later after 


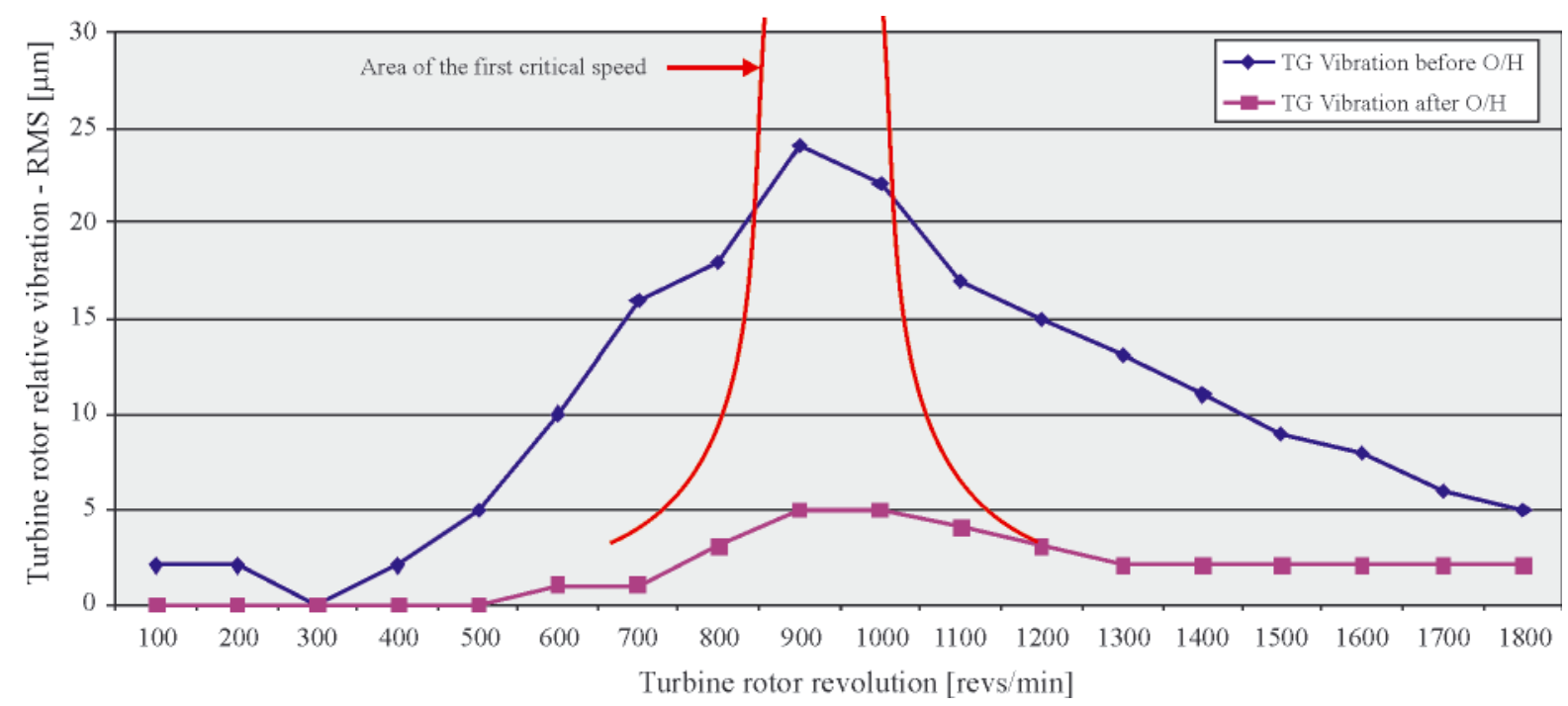

Fig. 3. RMS value changes of turbine rotor's relative vibration signal in the turbogenerator idling at various revolutions - for two technical states: before and after overhaul $\mathrm{o} / \mathrm{h}$, with the indicated area of the first critical speed

turbogenerator overhaul (see Fig. 2 and 3), a significant increase of the vibration level is observed, which suggests worsening of the technical/dynamic state of the turbogenerator. Despite the elimination of external disturbances caused by different states of ship load, hydro-meteorological conditions and/or the work of other engines and equipment, repeated measurements confirmed the increased unserviceability of the turbogenerator. Unfortunately, it was not possible to determine its location and source. Taking into consideration the location of the measuring transducer and the nature of the wear observed in the turbogenerator bearings it was assumed that a very likely reason of the noticeable increase of the vibration level was the increased clearance in the turbine bearing (Fig. 1a, point. 1).

The operating experience gained so far [8] suggests that the currently used operational methods and procedures are inadequate and insufficient. Their effectiveness and credibility depend on a proper assessment done by a human operator and his/her ability to use the archived information.

The lack of the fault development trend analysis limits the diagnosis of the turbogenerator operation to a two-state form: good condition - the state of fitness/technical ability, or poor condition - the state of unfitness/technical inability. Such an approach makes it impossible to assess the time of nearing the state of unfitness even if there is only a partial state of fitness.

Therefore the scope of the diagnosis performed for maintenance purposes needs to be extended by a trend-based diagnostic inference making use of an additional apparatus for measuring characteristic parameters of turbogenerator vibration $[4,6]$.

\section{ASSESSING THE TECHNICAL STATE OF THE TURBOGENERATOR WITH THE AID OF VIBRATION DIAGNOSTICS}

Since the manufacturing and installation technology was believed to be correct with respect to the examined turbogenerator, further research was oriented on searching for operating reasons of the observed changes of turbogenerator's dynamic state which manifested themselves by elevated bearing vibration amplitudes. The intensity and nature of such vibrations depend on, among other factors, unbalanced mass inertia, quality of the alignment, thermal deformations, and/or bearing operation conditions [6].

In this situation it was decided to perform additional measurements of turbogenerator dynamics. It was done by an external service team with the aid of the Schenk apparatus and the measuring instrument Yibroport with the module for RMS velocity measurement [7]. The absolute vibrations were measured using a piezoelectric velocity transducer with a magnetic base mounted on a flat surface of the machine bearing housing, see the diagram in Fig. 4. The measurements were done in the vertical (V), horizontal (H) and axial (A) directions.

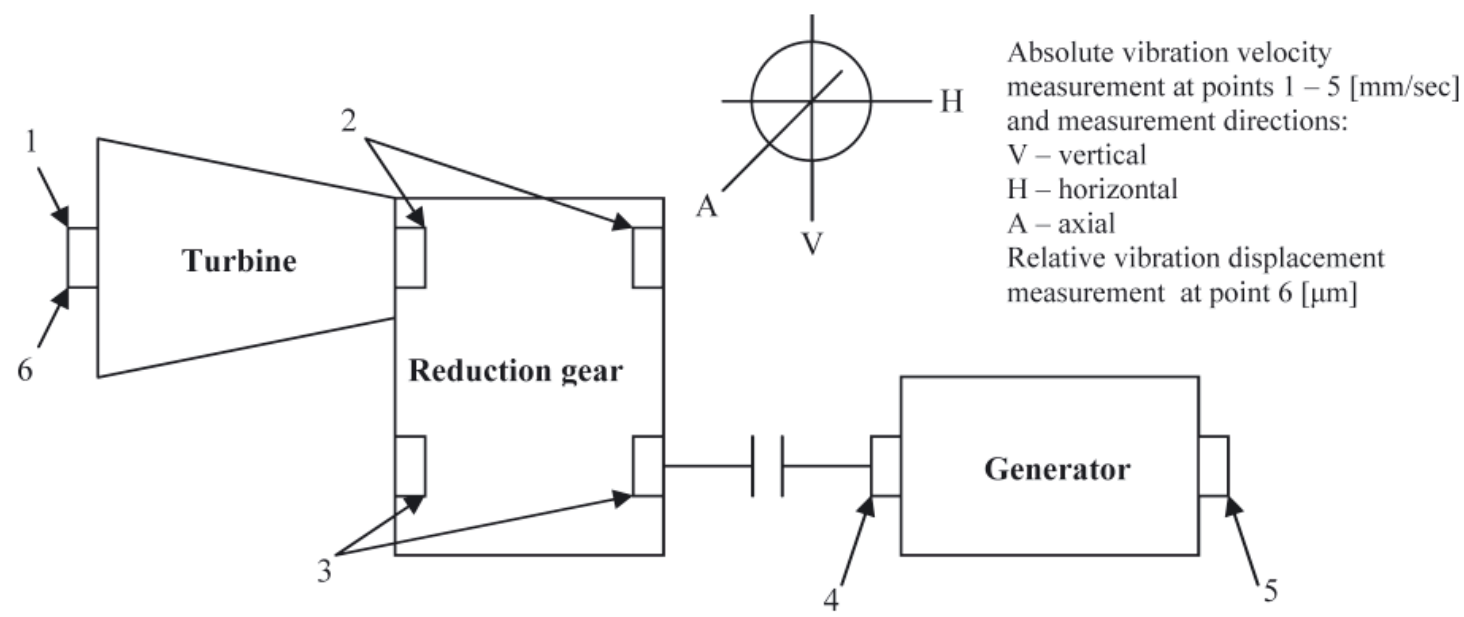

Fig. 4. Schematic distribution of vibration signal measurement points in steam turbogenerator: 1) and 6) turbine rotor bearing, 2) reduction gear pinion bearings, 3) reduction gear wheel bearings, 4) generator bearing turbine side, 5) generator bearing free end side 
Tab. 2. RMS values of absolute bearing house vibration velocities, measuring points 1-5, and relative turbine rotor/bearing vibration, point 6 , for various turbogenerator loads and nominal speed $1800 \mathrm{rev} / \mathrm{min}$

\begin{tabular}{|c|c|c|c|c|c|c|c|c|c|c|c|c|c|c|c|c|}
\hline \multirow{2}{*}{ kW } & \multicolumn{3}{|c|}{1} & \multicolumn{3}{|c|}{2} & \multicolumn{3}{|c|}{3} & \multicolumn{3}{|c|}{4} & \multicolumn{3}{|c|}{5} & 6 \\
\hline & V & H & $\mathbf{A}$ & V & H & $\mathbf{A}$ & V & H & $\mathbf{A}$ & V & H & $\mathbf{A}$ & V & H & $\mathbf{A}$ & V \\
\hline 0 & 0.72 & 1.69 & 1.25 & 0.84 & 1.44 & 0.87 & 0.89 & 1.31 & 0.85 & 0.93 & 0.88 & 1.50 & 1.55 & 0.61 & 1.29 & 5 \\
\hline 180 & 0.69 & 1.49 & 1.64 & 0.88 & 1.02 & 1.18 & 0.94 & 1.16 & 1.24 & 1.05 & 0.91 & 1.50 & 1.92 & 0.63 & 1.71 & 9 \\
\hline 530 & 0.86 & 1.44 & 1.66 & 0.65 & 1.18 & 1.01 & 0.86 & 1.18 & 0.85 & 0.97 & 0.72 & 0.99 & 1.31 & 0.64 & 1.15 & 17 \\
\hline 880 & 2.11 & 1.52 & 2.74 & 0.90 & 1.07 & 0.93 & 0.99 & 1.21 & 0.76 & 0.86 & 0.66 & 0.90 & 1.20 & 0.68 & 1.03 & 27 \\
\hline
\end{tabular}

The measured RMS values of the absolute bearing house vibration velocities, the measuring points $1-5$, and of the relative turbine rotor/bearing vibration, point 6 , are collected in Tab. 2 for different turbogenerator loads and the rated speed of $1800 \mathrm{rev} / \mathrm{min}$ [7].

Tab. 3 collects the reference criteria for assessing the dynamic state a turbogenerator taking into account the acceptable and limited RMS velocity values $[4,5,6]$. These criteria make the basis for creating a set of quantities being comparison classifiers. The obtained results were compared with the measured reference values from Tab. 3. The all specified measuring vibration levels were within the acceptable range, below $3 \mathrm{~mm} / \mathrm{s}$, and their values increased with the increasing turbogenerator load. However, the observed vibration levels were slightly higher than those recorded by other indications for the turbine bearings, especially in the axial direction of $2.74 \mathrm{~mm} / \mathrm{s}$. This trend was also reflected in the results of the measurements of the relative turbine rotor/bearing housing vibrations - 27 microns, recorded using a standard eddy-current displacement transducer installed by the producer. The results of the measurements have proved that the turbogenerator was in state of partial fitness with the reduced technical performance of the turbine bearing of concern. It was the reason why the verification of its technical state with the suggested need to replace the bearings was included to the scope of the incoming overhauling after utilization of the resource hours (TBO - Time Base Overhauling).

In order to enhance the results of the diagnostic inference, the measured vibration signals were analyzed using spectral analysis and the fast Fourier transform FFT [9]. The results of the analysis of the $1^{\text {st }}$ and $2^{\text {nd }}$ order harmonics for various turbogenerator loads are shown in Tab. 4 [7].

The values and amplitudes of the $1^{\text {st }}$ and $2^{\text {nd }}$ order harmonics of particular frequencies measured at points 1-5 reveal the similar nature as in the time domain, with the elevated vibrations indicated by higher 1 st order harmonics for the turbine bearing, at the $2^{\text {nd }}$ order harmonics close to zero. This may indicate an increased bearing clearance - point 1, Tab. 4 and Fig. 5 a-c. On the other hand, at point 2 Tab. 4 the harmonic components of the $1^{\text {st }}$ and $2^{\text {nd }}$ order do not reveal increased values and do not indicate changes in the dynamic state of the turbogenerator at this measuring point.

The analysis of the harmonic amplitudes of vibration signals measured at points 3 and 4 Tab. 4 shows the increased $2^{\text {nd }}$ order harmonics which may indicate a slight (permissible) unbalance of the turbine rotor. However, by comparing the frequency of the vibration amplitude waveform at the measuring point 6 , Tab. 4 and Fig. 6 we can notice that there are increased values for both the $1^{\text {st }}$ and $2^{\text {nd }}$ order harmonics which may be associated with a slight (permissible) alignment deviation.

Tab. 3. Ranges of absolute vibration velocity RMS values which classify the dynamic state of turbogenerator [mm]

\begin{tabular}{|c|c|}
\hline $\mathbf{0 - 2 . 8}$ & $\begin{array}{r}\text { Small vibration. Low wear of bearing. Low noise level. State of operational suitability/technical efficiency. } \\
\text { Good condition, no disability. }\end{array}$ \\
\hline $\mathbf{2 . 8 - 7 . 1}$ & $\begin{array}{r}\text { Noticeable vibration, often caused by increased wear of bearings. Increased noise level. Needs to find a reason, } \\
\text { plan inspection/repair in the near future. The need for additional measurements and observations. Status of partial/ } \\
\text { incomplete technical efficiency. Sufficient state, small/partial damage. Plan the repair. }\end{array}$ \\
\hline $\mathbf{7 . 1 - 1 8}$ & $\begin{array}{r}\text { High level of noise and vibration. Too high temperature of bearings. Loss of oil film. Wear. Need to stop and } \\
\text { perform inspection/repair. State of unfitness/technical malfunction. The state of need for improvement, dangerous } \\
\text { damage. Do the repair. }\end{array}$ \\
\hline $\begin{array}{r}\text { Very high level of noise and vibration. Damage to the machine, emergency stop. The need for repair. State } \\
\text { of unfitness/technical malfunction. Unacceptable state, catastrophic damage. Immediately stop the engine. } \\
\text { Turbogenerator should be stopped automatically by safety systems. }\end{array}$ \\
\hline
\end{tabular}

Tab. 4. $1^{\text {st }}$ and $2^{\text {nd }}$ order harmonics of the absolute vibration velocity signals recorded at measuring points 1-5 for different turbogenerator loads and revolutions $1800 \mathrm{rev} / \mathrm{min}$

\begin{tabular}{|c|c|c|c|c|c|c|c|c|c|c|c|c|c|c|c|c|}
\hline \multirow{2}{*}{$\mathbf{k W}$} & \multirow{2}{*}{$\mathbf{H}$} & \multicolumn{3}{|c|}{1} & \multicolumn{3}{|c|}{2} & \multicolumn{3}{|c|}{3} & \multicolumn{3}{|c|}{4} & \multicolumn{3}{|c|}{5} \\
\hline & & V & $\mathbf{H}$ & $\mathbf{A}$ & V & H & $\mathbf{A}$ & V & H & $\mathbf{A}$ & V & $\mathbf{H}$ & $\mathbf{A}$ & V & H & $\mathbf{A}$ \\
\hline \multirow[t]{2}{*}{0} & $1 \mathrm{~N}$ & 0.13 & 0.13 & 0.37 & 0.23 & 0.27 & 0.10 & 0.13 & 0.37 & 0.10 & 0.71 & 0.29 & 0.54 & 0.34 & 0.20 & 0.47 \\
\hline & $2 \mathrm{~N}$ & 0.10 & 0.02 & 0.03 & 0.01 & 0.03 & 0.01 & 0.17 & 0.61 & 0.34 & 1.15 & 0.37 & 0.78 & 0.81 & 0.34 & 0.68 \\
\hline \multirow[t]{2}{*}{180} & $1 \mathrm{~N}$ & 0.37 & 0.27 & 0.82 & 0.37 & 0.27 & 0.06 & 0.30 & 0.34 & 0.30 & 0.20 & 0.17 & 0.78 & 0.27 & 0.06 & 0.41 \\
\hline & $2 \mathrm{~N}$ & 0.03 & 0.03 & 0.06 & 0.03 & 0.03 & 0.03 & 0.47 & 0.47 & 0.54 & 0.34 & 0.27 & 1.26 & 0.47 & 0.13 & 0.47 \\
\hline \multirow[t]{2}{*}{530} & $1 \mathrm{~N}$ & 0.55 & 0.40 & 0.88 & 0.26 & 0.14 & 0.20 & 0.47 & 0.39 & 0.60 & 0.55 & 0.2 & 0.13 & 0.89 & 0.13 & 0.57 \\
\hline & $2 \mathrm{~N}$ & 0.1 & 0.01 & 0.01 & 0.01 & 0.01 & 0.01 & 0.10 & 0.58 & 0.13 & 0.2 & 0.27 & 0.4 & 0.15 & 0.08 & 0.08 \\
\hline \multirow[t]{2}{*}{880} & $1 \mathrm{~N}$ & 1.4 & 0.52 & 1.9 & 0.46 & 0.28 & 0.32 & 0.48 & 0.50 & 0.46 & 0.64 & 0.33 & 0.42 & 0.78 & 0.32 & 0.39 \\
\hline & $2 \mathrm{~N}$ & 0.01 & 0.01 & 0.01 & 0.01 & 0.01 & 0.01 & 0.07 & 0.43 & 0.05 & 0.05 & 0.17 & 0.04 & 0.11 & 0.08 & 0.09 \\
\hline
\end{tabular}




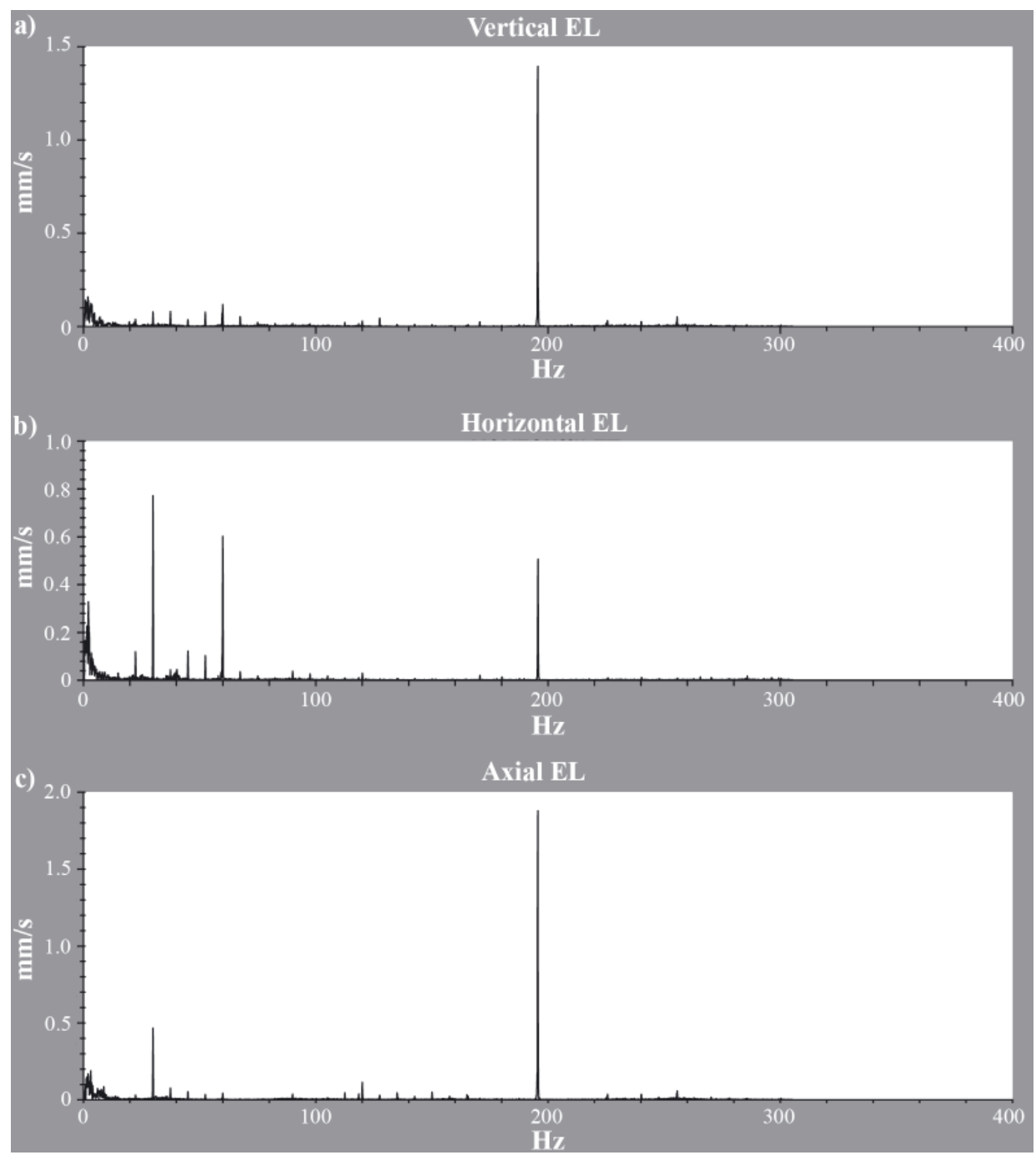

Fig. 5. Harmonic analysis of vibration signals measured in turbine rotor bearing at $880 \mathrm{KW}$ : a) vertical direction $(V)$, b) horizontal direction $(H)$, c) axial direction $(A)$

The spectral analysis of the waveforms and the $1^{\text {st }}$ and $2^{\text {nd }}$ order harmonic components confirm the conclusion formulated after time domain analysis about the technical state of the turbogenerator, in particular the state of the turbine rotor bearing, and the need for its overhaul. It also made it possible to infer about the dynamic state of other bearing nodes - other measuring points. The formulated conclusions and operational decisions were verified during turbogenerator overhaul in a shipyard.

\section{TURBOGENERATOR REPAIR INSPECTION}

During the verification, traces of normal/operational wear were observed on both active and passive reduction gear wheels and in their bearings, and also in the generator bearing on the turbine side and in the turbine and gear thrust bearings. The results of relevant clearance measurements done in these bearings are given in Tab. 5, entries 2-8, the presented values are within the design ranges [3]. However, significant traces of wear were observed on the lower shell in the turbine rotor bearing, see Fig. 7a, which was confirmed by visual/organoleptic inspection and measurement of bearing clearance, see Tab. 5, position 1 . These results slightly exceeded the acceptable values. In the generator bearing, traces of wear were observed on the edges of the outer working surface of the upper shell on the free end of the shaft, see Fig. 7b. This may indicate a slight misalignment between the generator and reduction gear shafts on the side of the passive wheel, as a possible consequence of relatively low precision of assembly. The measured values of the bearing clearance were equal to the design dimensions given in Tab. 5, position 9. Fig. 7 shows the observed traces of operational wear on the working surfaces of the turbogenerator bearing shells which were replaced with new ones during the dry-dock overhaul.

Tab. 5. Design clearances and clearance measurements in AT42M type turbogenerator journal bearings

\begin{tabular}{|c|c|c|c|c|}
\hline \multirow{2}{*}{ Bearing name } & \multicolumn{2}{|c|}{ Design clearances $[\mathrm{mm}]$} & \multicolumn{2}{|c|}{ Measured clearances [mm] } \\
\hline & Turbine side & Generator side & Turbine side & Generator side \\
\hline Turbine rotor bearing (1) & \multicolumn{2}{|c|}{$0.100-0.166$} & \multicolumn{2}{|c|}{0.175} \\
\hline Pinion bearings (2 and 3) Reduction gear & \multicolumn{2}{|c|}{$0.328-0.365$} & 0.330 & 0.290 \\
\hline Wheel bearings ( 5 and 6) Reduction gear & \multicolumn{2}{|c|}{$0.125-0.175$} & 0.160 & 0.175 \\
\hline Generator bearings ( 8 and 9 ) & \multicolumn{2}{|c|}{0.175} & 0.170 & 0.175 \\
\hline Thrust bearings (4 and 7) & $0.250-0.300$ & $0.300-0.524$ & 0.300 & 0.340 \\
\hline
\end{tabular}




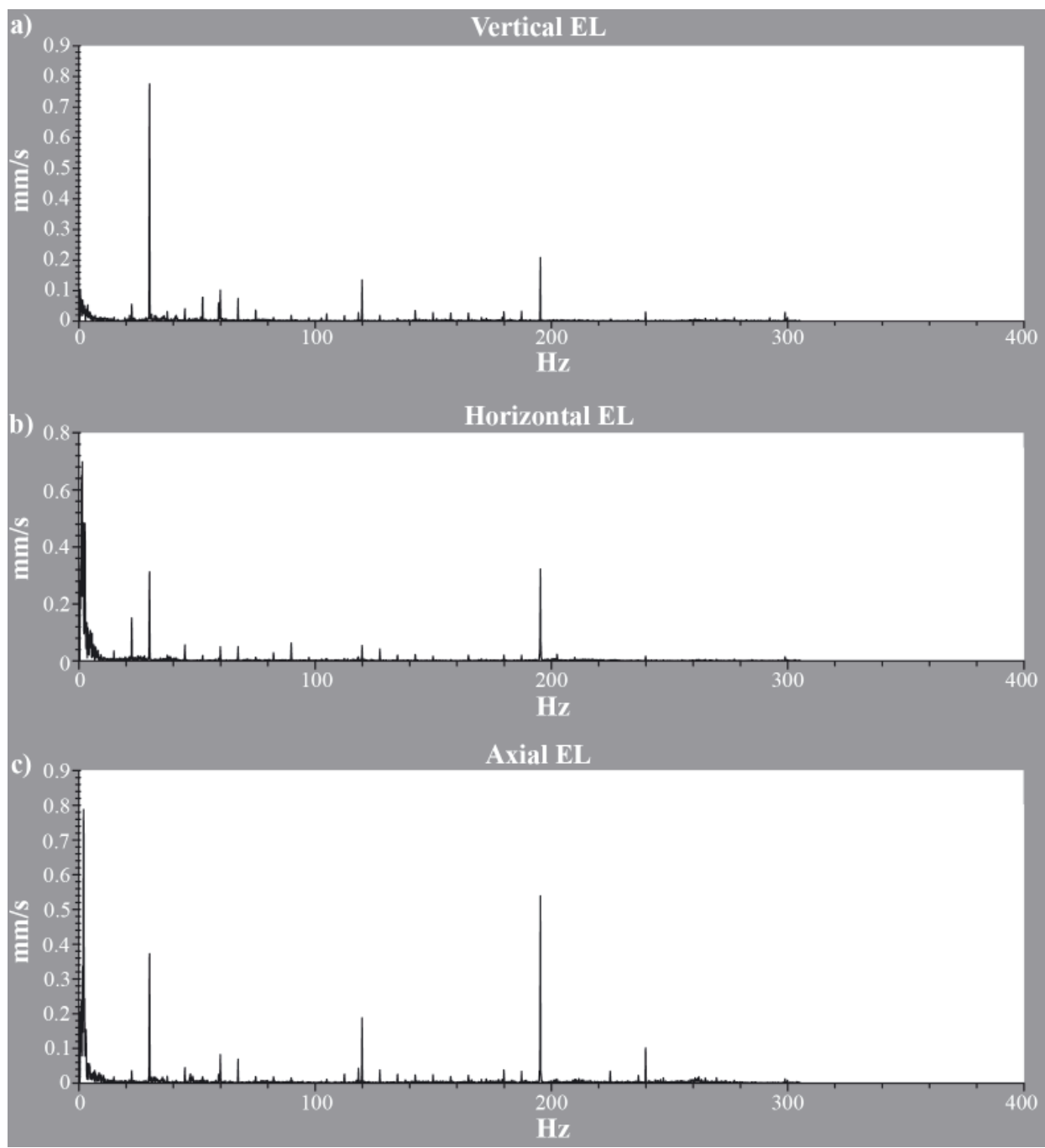

Fig. 6. Harmonic analysis of vibration signals measured in generator free end bearing at $880 \mathrm{KW}$ : a) vertical direction $(V), \boldsymbol{b})$ horizontal direction $(H), \boldsymbol{c})$ axial direction $(A)$
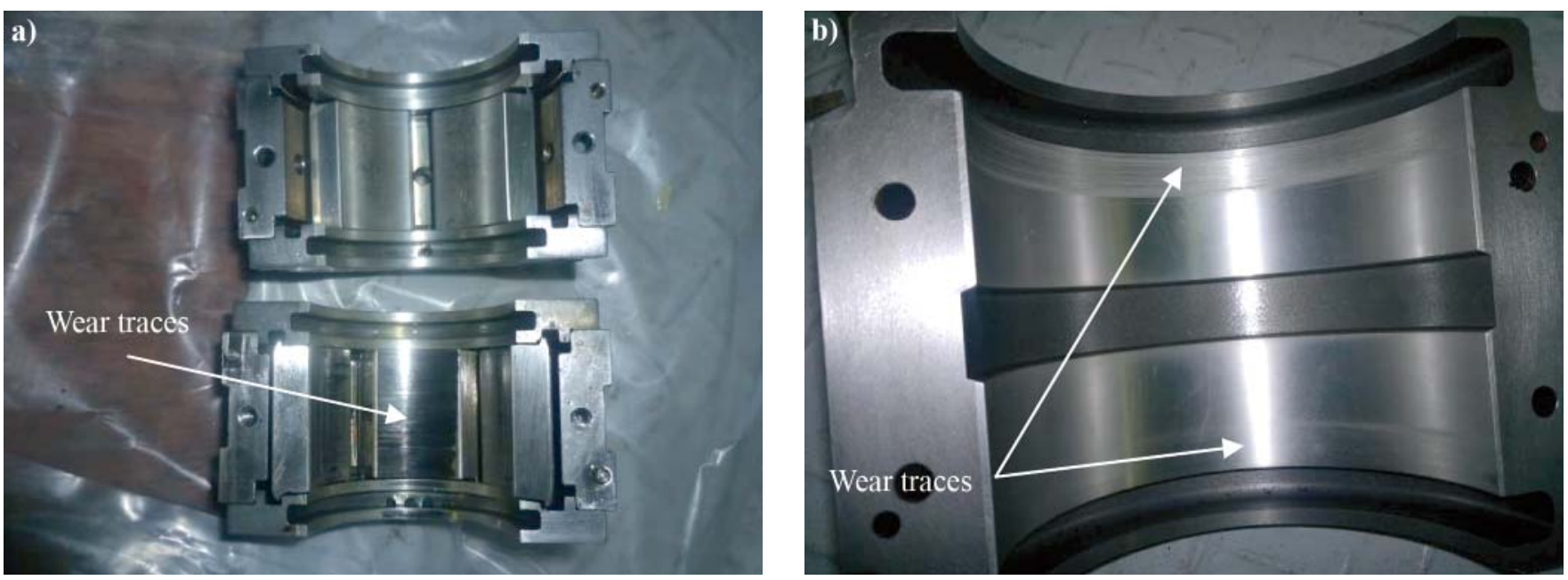

Fig. 7. Operational wear traces in turbogenerator type AT42M bearings: a) turbine rotor bearing 1 steam exhaust side; b) bottom half of generator free end bearing 5

Taking into account the values of the recorded clearances (Tab. 5 position 1 and 9), the state of the bearings 1 and 5 (Fig. 4), was classified as partially fit and conditionally accepted for further use/operation. However, due to the specific nature of the whole turbogenerator as the "critical equipment" for readiness task in a safe and trouble-free operation of the ship, and also the bearing themselves as critical spare parts on board, a decision was made to replace these bearings with new ones.
Within the framework of comprehensive evaluation of the technical state of turbogenerator components, the measurements of turbine shaft runout in specific control planes were done. The measurements showed slight deviation of the measured values from zero, of an order of $+/-0.02 \mathrm{~mm}$, thus proving the absence of shaft deflection due to thermal deformation. The measurements of the turbine rotor unbalance which were done at the dynamic balancer indicated the unbalance values not 
exceeding 10 grams: 8.0 grams in the turbine bearing support area, and 6.4 grams for the reduction gear of the active wheel bearing. These values were reduced to less than 1 gram, i.e. $990 \mathrm{mg}$ and 239, respectively [7].

\section{CONCLUSIONS}

- The confrontation of the results of technical state verification of the examined turbogenerator with the analysis of the vibration measurements shows that they are compatible. This justifies the opinion about correctness of the diagnostic inference based on the measured vibration signals in both the time and frequency domains. Moreover, the vibration diagnostics turned out to be a useful and reliable source of information on the dynamic state of the turbogenerator and its components.

- This conclusion was confirmed by further measurements performed after completing the overhaul and assembling the turbogenerator and its components, including the coaxial connection of gear and generator shafts - checking of coupling alignment, which showed a significant decrease in the relative turbine shaft/bearing vibrations (the RMS change curves after overhaul in Fig. 2 and 3). Absolute vibration measurements after repairs were not performed - this decision was made based on the results of the overhaul and subsequent turbogenerator operational performance reports.

- The presented method of turbogenerator service and maintenance indicates that it is advisable to include the trend analysis of changes of its technical components as an important tool in decision-making processes. This would require supplementing the method by predictive maintenance models of turbogenerator operation.

\section{BIBLIOGRAPHY}

1. Adamkiewicz A., Rutkowski J.: Operational evaluation of informational capacity of the operational supervision system of the auxiliary steam turbine on a FPSO type vessel (in Polish). Postępy Nauki i Techniki nr 11, Lublin 2011.

2. Adamkiewicz A., Michalski R., Zeńczak W: Selected problems of energy conversion in marine power systems (in Polish). Wydawnictwo KAPRINT, Lublin 2012.

3. Instruction Book for Main Turbogenerator Turbine type AT42M. Mitsubishi Heavy Industry Ltd., Nagasaki 15.09.2004.

4. Kozak M.: Steam turbine structure and maintenance control methods (in Polish). Wydawnictwo KAPRINT, Lublin 2008.

5. Niziński S., Michalski R.: Maintenance of vehicles and machines (in Polish). Wydawnictwo Instytutu Technologii Eksploatacji, Radom 2007.

6. Orłowski Z.: Diagnostics in steam turbines' life (in Polish). Wydawnictwo Naukowo-Techniczne, Warszawa 2001.

7. Service and Dynamic Balancing Reports. Viking Engineering Ltd., Singapore 13.06.2012.

8. Summary of Marine Engine Trouble Cases, Auxiliary Turbine Engine 01.1989 - 12.2003. All Japan Seaman's Union, Tokyo 2004.

9. Żółtowski B.: Machine dynamics investigations (in Polish). Akademia Techniczno-Rolnicza, Bydgoszcz 2002.

\section{CONTACT WITH THE AUTHORS}

Andrzej Adamkiewicz, Assoc. Prof. Jan Drzewieniecki, Ph.D.

Department of Condition Monitoring \& Maintenance of Machinery

Maritime University of Szczecin ul. Podgórna 52/53, 70-205 Szczecin, POLAND tel.: +48 91 4338123, fax: +48 914318542 e-mail: a.adamkiewicz@am.szczecin.pl e-mail: j.drzewieniecki@am.szczecin.pl 